\title{
Relato de uma Experiência Inovadora em um Curso de EJA na Modalidade EAD Semipresencial no ensino fundamental público
}

\author{
Igor Kühn', Francisco Dutra dos Santos Jr. ${ }^{1}$, Leandro Krug Wives ${ }^{1}$, \\ Mariete Ferrari \\ ${ }^{1}$ CINTED/PPGIE - Universidade Federal do Rio Grande do Sul (UFRGS) \\ ${ }^{2}$ Escola Municipal de Ensino Fundamental Fidel Zanchetta- Cacheirinha- RS \\ prof.chicosantosjr@gmail.com,kuhnigor@gmail.com, \\ wives@inf.ufrgs.br, mariete.ferrari@hotmail.com
}

\begin{abstract}
One of the biggest challenges of Youth and Adult Education (EJA) in elementary school, over the years of operation at the school where the project is being carried out, has been to reduce the rates that involve school gap, as well as to combat high levels of dropout. and disapproval. To this end, the EJA Semi-presential Distance Learning was structured as a more flexible pedagogical proposal that takes into account the particularities and experiences of learners without giving up quality. For this purpose, it has developed its own structure regarding curriculum organization, duration, school regime. and methodology
\end{abstract}

Resumo. Um dos maiores desafios da Educação de Jovens e Adultos (EJA) no ensino fundamental, ao longo dos anos de funcionamento na escola em que o projeto é realizado, tem sido reduzir os índices que envolvem a defasagem escolar, bem como combater níveis elevados de evasão e reprovação. Para tanto, a EJA EaD Semipresencial foi estruturada como uma proposta pedagógica mais flexível que leva em consideração as particularidades e as experiências dos educandos sem com isso abrir mão da qualidade. Para isso foi desenvolvida uma estrutura própria quanto à organização curricular, duração, regime escolar e metodologia.

\section{Introdução}

Com o avanço e popularização das Tecnologias da Informação e da Comunicação (TICs) surgiram os cursos a distância com o uso da Web, sendo esses ofertados em diferentes níveis de ensino. Esses cursos são favorecidos por uma infraestrutura que possui uma tendência a reduzir seus custos, tornando possível uma maior abrangência geográfica, atendendo a diversos segmentos sociais e regiões, antes não alcançados. $\mathrm{O}$ crescimento do número de cursos ofertados na modalidade a distância $(\mathrm{EaD})$ tem levado a estudos sobre as particularidades dessa modalidade de ensino e a melhor forma de implementação dos cursos, tendo como principal objetivo a adequação ao público a ser atendido. Um dos conceitos dessa modalidade é apresentado por Moore: 
VIII Congresso Brasileiro de Informática na Educação (CBIE 2019)

Anais do VIII Workshop de Desafios da Computação aplicada à Educação (DesafIE 2019)

"Educação a distância é o aprendizado planejado que ocorre normalmente em um lugar diferente do ensino, o que requer comunicação por meio de tecnologias e uma organização instrumental especial.” (2007, p.25)

A Educação de Jovens e Adultos, na modalidade $\mathrm{EaD}$, vem contribuir na formação desses cidadãos que por motivos diversos não puderam cursar o ensino fundamental no considerado tempo "normal", pois, enquanto modalidade educacional de ensino visa a mediação didático-pedagógica nos processos de ensino e de aprendizagem que ocorrem, também, com a utilização das TICs com e entre educandos e professores.

Em especial esse projeto utilizou a EaD com um público específico de alunos EJA, a partir dessa combinação é possível relatar a experiência realizada. Os alunos desse estudo são formados por dois grupos: o primeiro é caracterizado, principalmente, por educandos adolescentes ou adultos jovens que abandonaram o ensino regular por motivos de indisciplina, fracasso escolar ou estão vulneráveis socialmente. O segundo grupo refere-se a adultos que, em dado momento da vida, precisaram abandonar os estudos para trabalhar e ajudar no sustento familiar.

\section{A Experiência}

O curso funciona com um limite máximo de duzentos educandos distribuídos nos quatro BLOCOS (6 ao 9). Na primeira semana do curso, em todos os BLOCOS, os alunos são apresentados aos professores formadores. Na segunda semana, eles conhecem seu professor tutor-pesquisador, bem como recebem orientações sobre o uso e acesso da plataforma de ensino (Moodle). As aulas ocorrem duas vezes por semana de maneira presencial, conforme cronograma organizado pela equipe pedagógica e divulgado previamente nas primeiras aulas presenciais. Contudo, toda a organização do andamento do curso também está disponível na plataforma de ensino. O curso dispõe de um professor-tutor pesquisador por bloco. Cada tutor é responsável por um bloco específico e entre suas atribuições estão a interação com o ambiente de ensino e a aprendizagem proposta; os materiais didáticos produzidos pelos especialistas (professores formadores); a organização do tempo/espaço de sua própria instituição; o contexto institucional; o processo de aprendizagem de seus educandos; a validação dos materiais pedagógicos antes da publicação; o corpo docente, auxiliando-os no processo digital.

A organização do currículo foi constituída em torno de temas e problemas reais da comunidade escolar, dando ênfase aos conteúdos vivos, concretos e indissociáveis, aos quais os educandos se sintam envolvidos e aprendam a pesquisar e a procurar fontes de informação selecionando-as, ordenando-as, interpretando-as e divulgando-as, trabalhando no contexto diário a ideia de colaboração, diálogo, convivência e espírito crítico.

$\mathrm{Na}$ EJA EaD Semipresencial o educando é avaliado constantemente mediante realização das atividades (presenciais e on-line). Contudo, a maioria das atividades on-line tem o tempo determinado de duas semanas para serem realizadas. Após este período, as atividades só poderão ser realizadas no período de recuperação.

\section{Resultados Parciais}

O tipo de aluno objeto de estudo, faz parte de um enorme contingente de estudantes que acessam a EJA e que até a poucas décadas não utilizavam as novas tecnologias educacionais como a plataforma Moodle, fator esse que também atribui ao projeto um caráter de inclusão digital. Houve uma melhoria em relação a permanência dos alunos no curso, 
VIII Congresso Brasileiro de Informática na Educação (CBIE 2019)

Anais do VIII Workshop de Desafios da Computação aplicada à Educação (DesafIE 2019)

com a mensuração constante dos índices de evasão e a melhora dos processos didáticos.

Cabe ainda destacar que a modalidade ofertada pela escola possui um alto grau de ineditismo quando disponibiliza uma modalidade de educação a distância a um publico que até então não possuía acesso a esse formato de escola em que ferramentas digitais possuem uma importância fundamental na função de mediação entre Professores/ Tutores e os alunos do ensino fundamental da EJA.

\section{Dificuldades e Ações Futuras}

Como um dos desafios futuros, se busca a adequação da plataforma e dos recursos educacionais ao público usuário, ou seja, alunos da EJA. A plataforma é utilizada de uma maneira em que conteúdos educacionais do ensino fundamental são disponibilizados de forma tradicional. O que se propõe é a análise dos materiais que estão sendo ofertados e uma adequação não só em relação ao perfil dos alunos, mas também a forma como são disponibilizados. Como exemplo, um mesmo material pode ser disponibilizado em forma de texto, áudio, vídeo, hiperdocumentos, etc. Também como proposta de melhoria em relação a plataforma é a disponibilização de todos os recursos quando a mesma for acessada por dispositivos móveis. Por meio de questionário aplicado aos alunos da EJA, foi constatado que em sua maioria acessa a plataforma por meio desses dispositivos. $\mathrm{O}$ resultado do questionário vem ao encontro de tendências presentes na educação contemporânea (Mobile Learning). Para realização dessas mudanças foi proposta uma cooperação entre a Escola Municipal de Ensino Fundamental Fidel Zanchetta localizada no Munícipio de Cachoeirinha região metropolitana de Porto Alegre e a UFRGS, por meio do Centro de Interdisciplinar de Novas Tecnologias em Educação (Cinted) tendo como agentes capacitadores os alunos doutorandos do Programa de Pós-Graduação em Informática na Educação (PPGIE). As melhorias deverão ocorrer por meio de intervenções técnicas na plataforma Moodle utilizada pela escola, bem como, com atividades de capacitação dos professores e tutores. Para finalizar, destacamos que as ações serão caracterizadas como um projeto de extensão da UFRGS, e que possui um caráter de gratuidade em relação às atividades que estão sendo e serão executadas. Tal posicionamento é fruto de uma compreensão por parte dos envolvidos de que esse tipo de ação deva ser prática recorrente em Universidades Públicas, devolvendo aos contribuintes em forma de serviços os impostos por eles pagos. Esse tipo contra partida da Universidade torna-se ainda mais relevante quando o público a ser atendido possui o perfil socio econômico dos alunos participantes desse estudo.

\section{Referências}

Rezende, F. A.(2009) “Educação especial e a EAD.” In: Litto, Frederic M.; Formiga, Marcos (Orgs.). Educação a distância: o estado da arte. São Paulo: Pearson Education do Brasil.

Tori, R. (2009) "Cursos híbridos ou blended learning.” In: Litto, Frederic M.; Formiga, Marcos (Orgs.). Educação a distância: o estado da arte. São Paulo: Pearson Education do Brasil.

Moore, M.; Kearsley, G.(2007) “A educação a distância integrada.” Trad. Roberto Galman. São Paulo: Thomson Learning.

Moran, J. M. et al. (2000) "Novas tecnologias e mediação pedagógica". 6. ed. Campinas. 